\title{
Sensorless Control of Four-Switch Inverter for Brushless DC Motor Drive and Its Simulation
}

\author{
Sathish Kumar Shanmugam1*, Meenakumari Ramachandran2, Krishna Kumar Kanagaraj1, \\ Anbarasu Loganathan ${ }^{3}$ \\ ${ }^{1}$ Department of EEE, Jansons Institute of Technology, Coimbatore, India \\ ${ }^{2}$ Department of EEE, Kongu Engineering College, Erode, India \\ ${ }^{3}$ Department of EEE, Erode Sengunthar Engineering College, Perundurai, India \\ Email: "sat_meae2k5@rediffmail.com
}

Received 1 March 2016; accepted 9 May 2016; published 12 May 2016

Copyright (C) 2016 by authors and Scientific Research Publishing Inc.

This work is licensed under the Creative Commons Attribution International License (CC BY). http://creativecommons.org/licenses/by/4.0/

(c) (i) Open Access

\section{Abstract}

The major function of this proposed research is to control the speed of the brushless DC motor with sensor less control for four-switch three phase inverter. This proposed system is simplified the topological structure of the conventional six-switch three phase inverter. In this proposed method, a new structure of four-switch three phase inverter [1] with reduced number of switches for system is introduced to reduce the mechanical commutation, switching losses that occur in the six-switch method. The proposed inverter fed brushless DC motor used in sensorless control schemes which is used for sensing positioning signals. To improve sensor less control performance, four-switch electronic commutation modes based proportional intergral controller scheme is implemented. In this four-switch three phase inverter reduction of switches, low cost control and saving of hall sensor were incorporated. The feasibility of the proposed sensor less control four-switch three phase inverter fed brushless DC motor drive is implemented, analysed using MATLAB/SIMULINK, effective simulation results have been validated out successfully.

\section{Keywords}

Brushless DC Motor, Four-Switch Three Phase Inverter, Proportional Integral Controller, Sensorless Control

\footnotetext{
${ }^{*}$ Corresponding author.
} 


\section{Introduction}

In recent times, the brushless DC motor is becoming popular in different applications because of its high efficiency, high power factor, lower maintenance, simple control and high torque. The proposed block diagram of the research is shown in the Figure 1. Usually, brushless motors are excited by six-switch three phase inverter as shown in Figure 3. On the other hand, cost-effective design is becoming one of the most imperative concerns for the modern motor control research. Several researchers with simulation [1] [2] developed new power inverters with condensed fatalities and expenses. Among these developments, the three-phase inverters with only four switches, as shown in Figure 2 is striking solution. In assessment with the normal three-phase voltage-source inverter with six switches, the most important descriptions of this proposed converter play dual role: the first is the reduction of switches and freewheeling diode count; the second is the reduction of conduction losses. They used position sensors to achieve commutation control of brushless DC motors. However, position sensors make the total system more expensive, larger in volume and a lesser amount of dependable. On the other hand, sensor control for six-switch three-phase brushless DC motors has had many successful applications. Almost all are sensor control schemes for six-switch three-phase brushless DC motors have to detect the zero-crossing point of voltage waveforms from unexcited windings to estimate position of the rotor; however it is not possible to accomplish sensorless control schemes. So four-switch three phase brushless DC motor is incorporated and various voltages output are carried out.

\section{Proposed Four-Switch Three Phase Inverter Brushless DC Motor Drive Systems}

Usually, Brushless DC motors are excited by Six-switch three phase inverter as shown in Figure 1, have lot of Commutation Problems and Switch Leg failure and large amount of Switching Losses. On the other hand, cost-

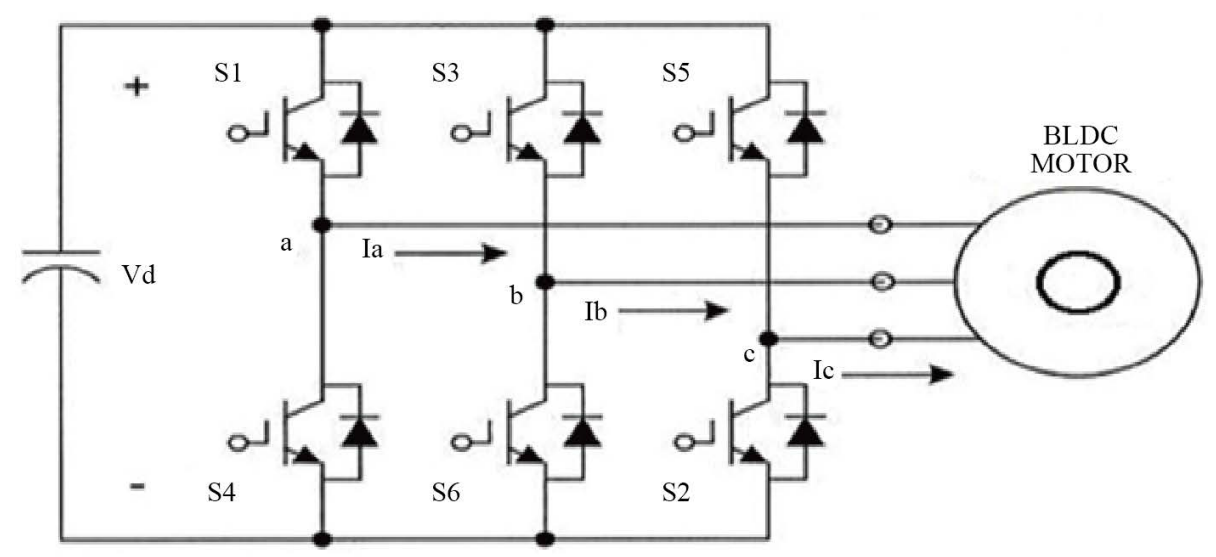

Figure 1. Conventional six-switch three phase inverter brushless DC motor drive systems.

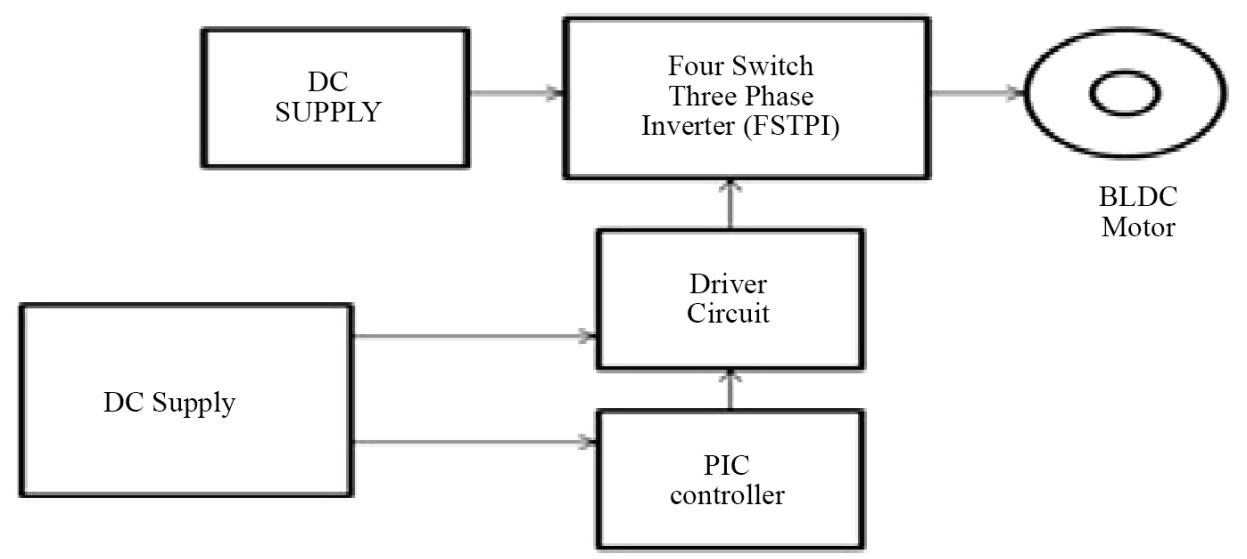

Figure 2. Block diagram of proposed four-switch three phase inverter brushless DC motor drive systems. 
effective design is becoming one of the most imperative concerns for the modern motor control research In order to Overcome this, Several researchers developed new Power inverters with condensed fatalities and expenses.

The three-phase inverters with only four switches, as shown in Figure 3 is striking solution for Six-Switch Inverter to reduce mechanical Strength and Switching Losses. In additional to that with the normal three-phase voltage-source inverter with Four switches, the most important descriptions of this proposed converter plays dual role i) the first is the reduction of Switches and Freewheeling diode count; ii) the second is the reduction of conduction losses. They used Position sensors to achieve commutation (Mechanical) control of Brushless DC motors.

The Proposed Four-switch three phase inverter Brushless DC Motor Drive Systems follows the switching sequence as shown in the Table 1.

Among the implements, the three phase inverters have only four switches, the main description of these proposed inverter are reduction of switches and conduction losses. Until now, reduced components have been applied in AC induction motor drives, however now a day the Brushless DC motor drives are using due to its high power factor, high speed, high torque, simple control and lower maintenance. The Four-Switch Three Phase Inverter (Four-switch Three Phase Inverter) used in six commutation modes based on current control and Sensor less control schemes. [2] developed Brushless DC motor drives with trapezoidal back electromotive force (EMF) using the Four-Switch Three-Phase Inverter. The four-space-vector scheme was used in the six commutation modes based on current control. In these Brushless DC drive configuration, the DC supply given to Fourswitch inverter it converts DC power to three phase AC power.

In proposed method single phase to three phase converter back end consists of four switches (T1 to T6). In three phase Brushless DC motor, two phases A and B are connected to the two legs of the Four-switch Three phase inverter and the third phase $\mathrm{C}$ is connected to the centre point of the capacitor. Phase $\mathrm{C}$ is directly connected to the Brushless DC motor, so the phase C current is not directly controlled [3].

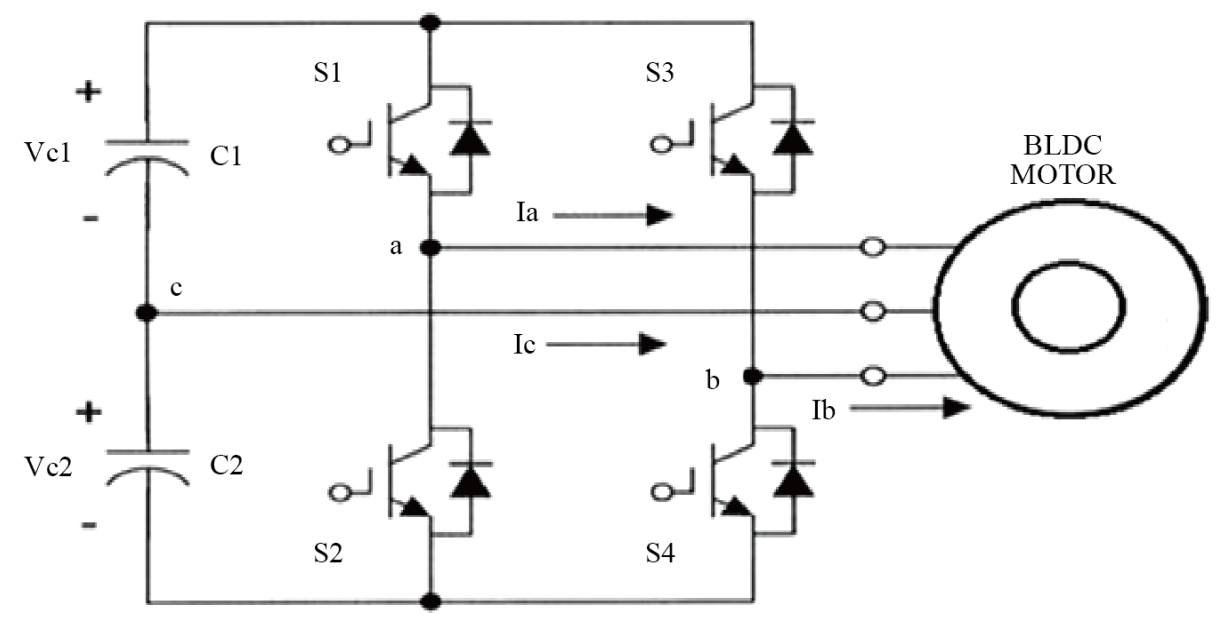

Figure 3. Proposed four-switch three phase inverter brushless DC motor drive systems.

Table 1. Switching sequence of four-switch three phase inverter.

\begin{tabular}{cccc}
\hline Modes & Active Phases & Silent phases & Switching devices \\
Mode I & Phases B and C & A \\
Mode II & Phases A and B & C & B \\
Mode III & Phases A and C & A \\
Mode IV & Phases B and C & C \\
Mode V & Phases A and B & And \\
Mode VI & Phases A and C & And \\
\hline
\end{tabular}




$$
\begin{aligned}
& S_{a}+S_{b}+S_{c}=0 \\
& S_{c}=-\left(S_{a}+S_{b}\right)
\end{aligned}
$$

Therefore, phase C indirectly controlled by phase A and phase B. For Brushless DC motors with a trapezoidal back EMF, is required to produce a constant electric torque. The proposed voltage Pulse Width Modulation(PWM) scheme for Four-switch three phase inverter requires six commutation modes which are $(\mathrm{X}, 0),(1$, $0),(1, X),(X, 1),(0,1)$ and $(0, X)[4]$. Here “X” stands for Don't care conditions.

\section{Back EMF Compensation}

As three-phase Brushless DC motor is motivated with six-step $120^{\circ}$ control process [5] [6]. Therefore the conduction interval of one phase is $120^{\circ}$. Therefore, the Back-EMF zero-crossing detecting performance is based on only two phases of a Brushless DC Motor.The Basic switching sequence of Four-switch three phase inverter available in SenSorless [7] [8] are shown in Table 1 are incorporated in this proposed work and their symbol parenthesis of the switch ON/OFF states are and indicates as (phases A and B). "X" denotes the ON and OFF state for both the high-side and low-side switching devices in the similar leg, " 1 " designates the ON condition used for the high-side switching device and "0" designates the OFF condition used for the low-side switching contrivance.

This conventional voltage PWM scheme provides a discharging loop between the capacitor and the low-side switch additionally causes non-rectangular stator current waveforms which are harmful for constant torque, as shown in Figure 4. Similar situations occur in Mode IV. There are three stages corresponding to $(0,0),(0,1)$ and $(1,0)$ correspondingly, in Mode II meant for the novel voltage Pulse width modulation method. Similar situations apply to Mode V. The new stage of this novel Pulse width modulation scheme in Modes II and V is introduced to turn OFF all power devices to prevent the capacitor discharging from the low-side switch. Furthermore, the supply voltages in Modes II and V are double of those in the other four Modes while the Pulse width moduation duty cycle in Modes I, III, IV of those in the Mode II and IV. The commutation sequence and the Pulse width modulation duty are shown in Table 1. Motor are connected to the power source at one time instant so the third phase can be used to detect zero-crossing [9] of the Back-EMF voltage performed by In general

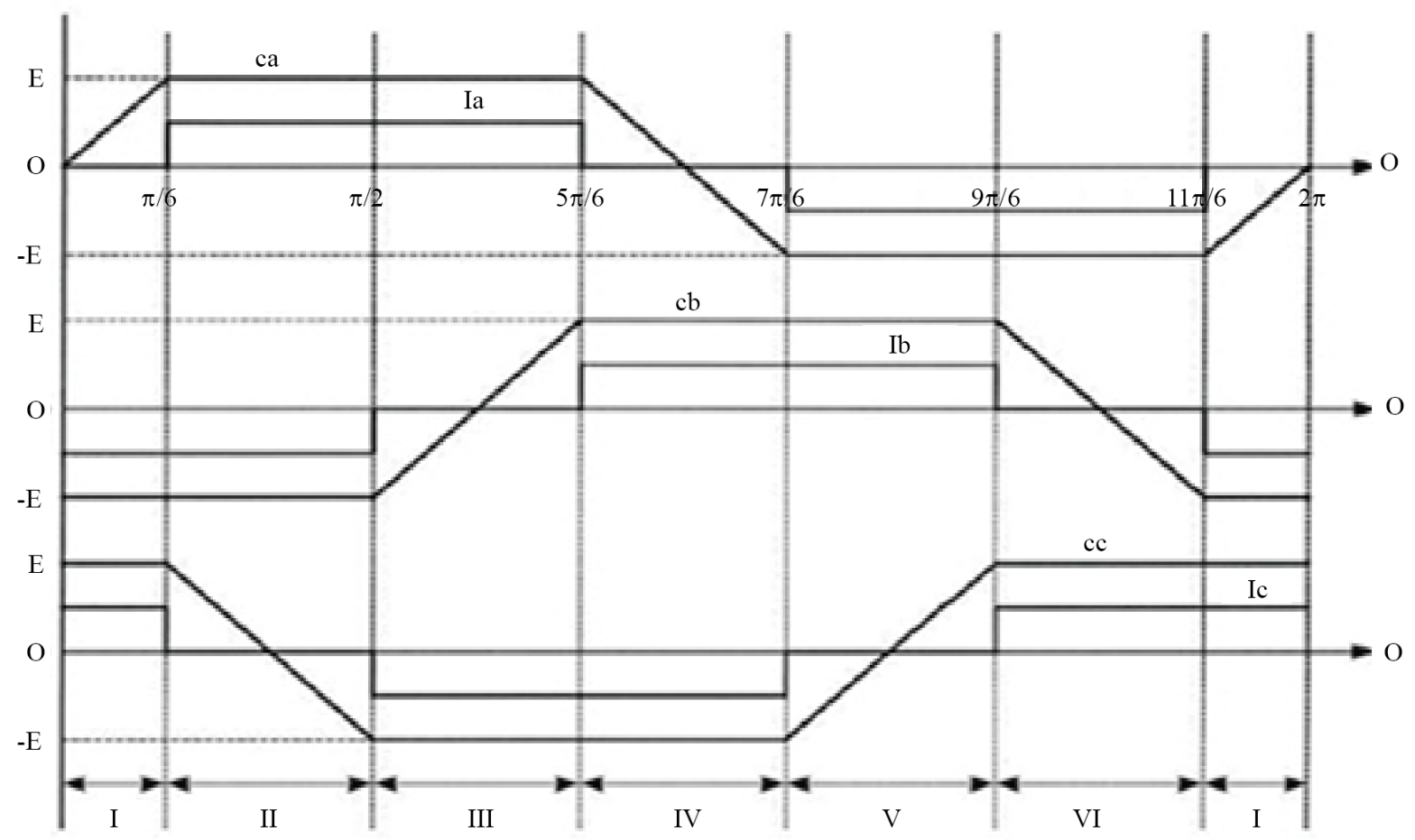

Figure 4. Back EMF and phase current waveforms of brushless DC motor. 
When phase A and phase B are connected to the source, phase C is floating. No current is going through this phase. This conducting interval lasts 60 electrical degrees, which is called commutation step. This is described by the following conditions:

If A phase High, B phase Low: which is analysed as general equations.

Normally,

$$
\begin{gathered}
£ a+£ b+£ c=0 \\
V_{a}=3 / 2_{e w}+V_{d c} / 2 \\
V_{b}=3 / 2_{e v}+V_{d c} / 2 \\
V_{c}=3 / 2_{e w}+V_{d c} / 2
\end{gathered}
$$

In these equations, forward voltage drop of Insulated bipolar transistor and freewheeling diode is ignored. However, in the four-switch converter based on the four switching operation, the generation of $120^{\circ}$ conducting and a $60^{\circ}$ non-conducting current profiles is essentially complicated. That resource the conventional Pulse width modulation schemes employed for four-switch induction motor drives cannot be directly applied to Brushless DC motor drives with sensorless [10]. This lead to the improvement of a novel control scheme called Direct Current Controlled Pulse width modulation scheme

\section{Results and Discussions}

The simulation of proposed research four-switch Brushless DC Motor is carried by Simulink and its Simulink model are shown if Figure 5.

To generate the pulse width modulation signals subsystems are proposed which is shown in Figure 6. The reference speed is set and rotor position sensor speed sensed are given to the controller if it is equal it is send to the controller or error is generated and rectified and it is given to the controller then the switches generates the Pulses.

The Pulse width modulation signals generated by the switches from the output of controller are shown in Figure 7. It is carried out by voltage and timeperiod and the results are taken from simulink environment.

The DC voltage which is fed an input supply gives the output after then rectification which is present inbuilt gives pure DC voltage of $40 \mathrm{~V}$ it also consists of voltage regulator whose output is shown in Figure 8.

The Brushless DC motor proposed in this research is three phase compare to [11] [12], from four-switch in-

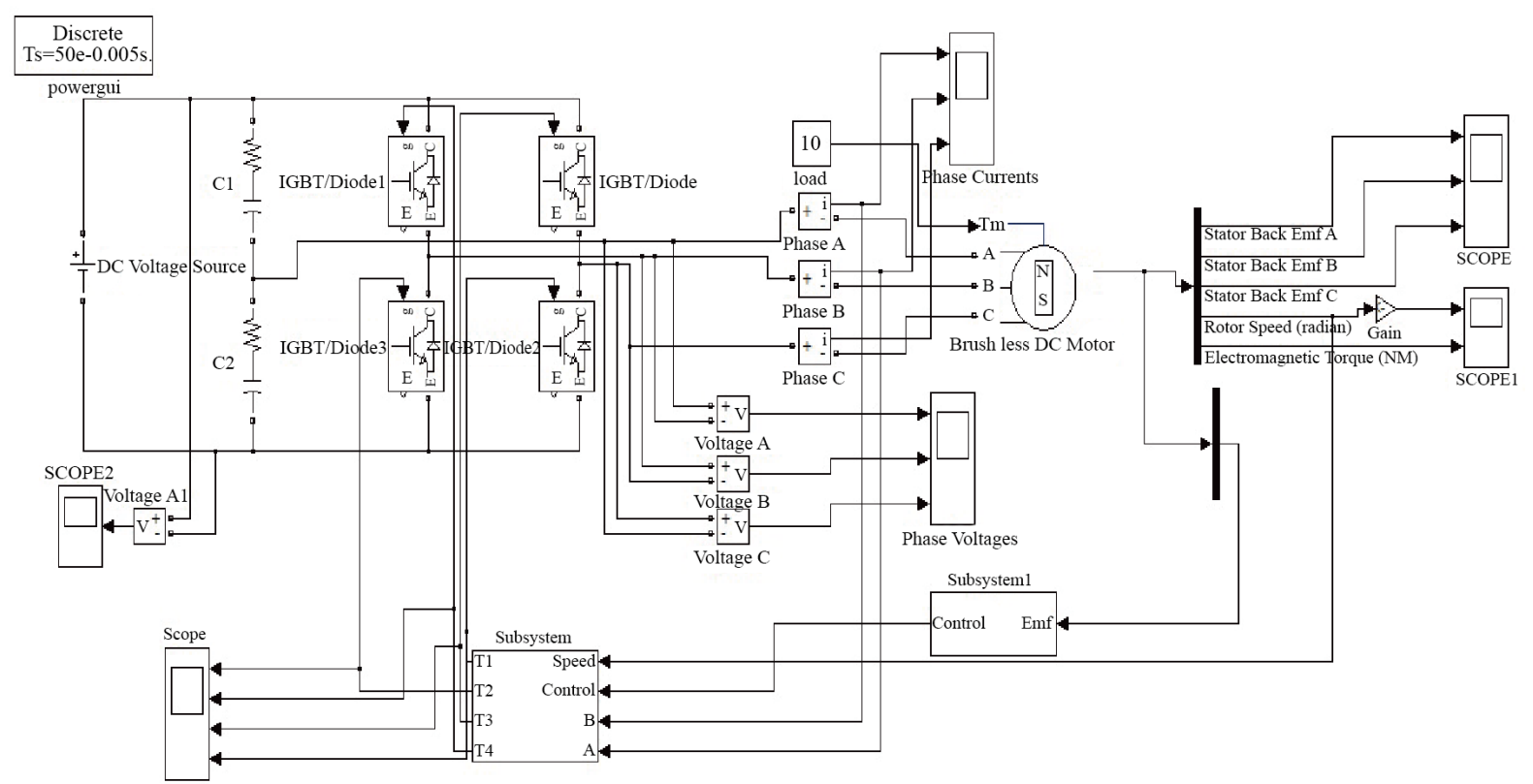

Figure 5. Simulation model of proposed four-switch three phase inverter system. 


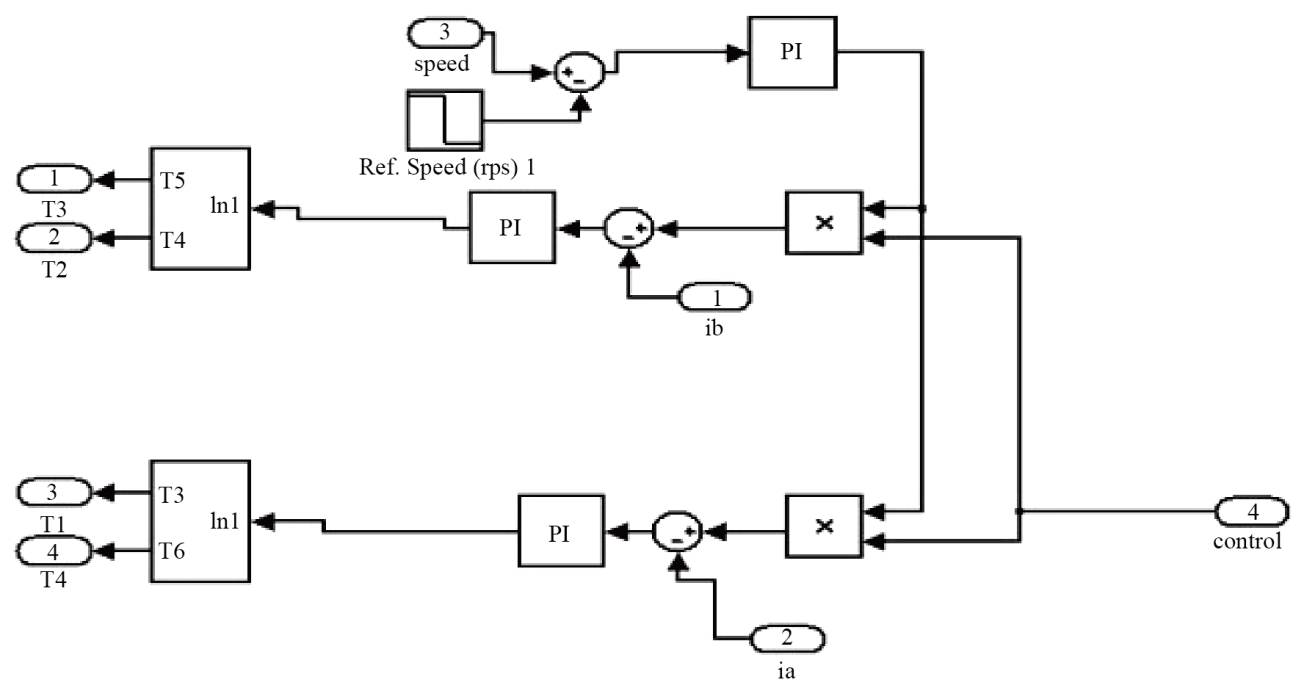

Figure 6. Subsystem of Pulse width modulation generation for switches (T1-T4).

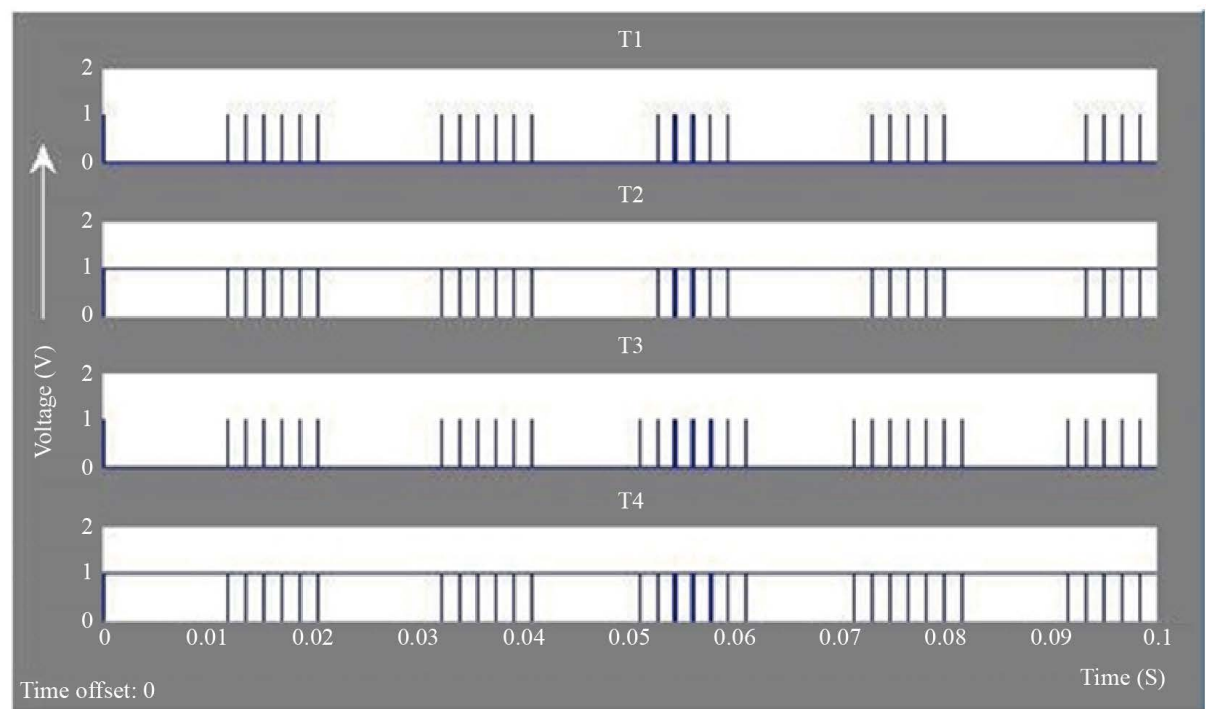

Figure 7. PWM generation for switches (T1-T4).

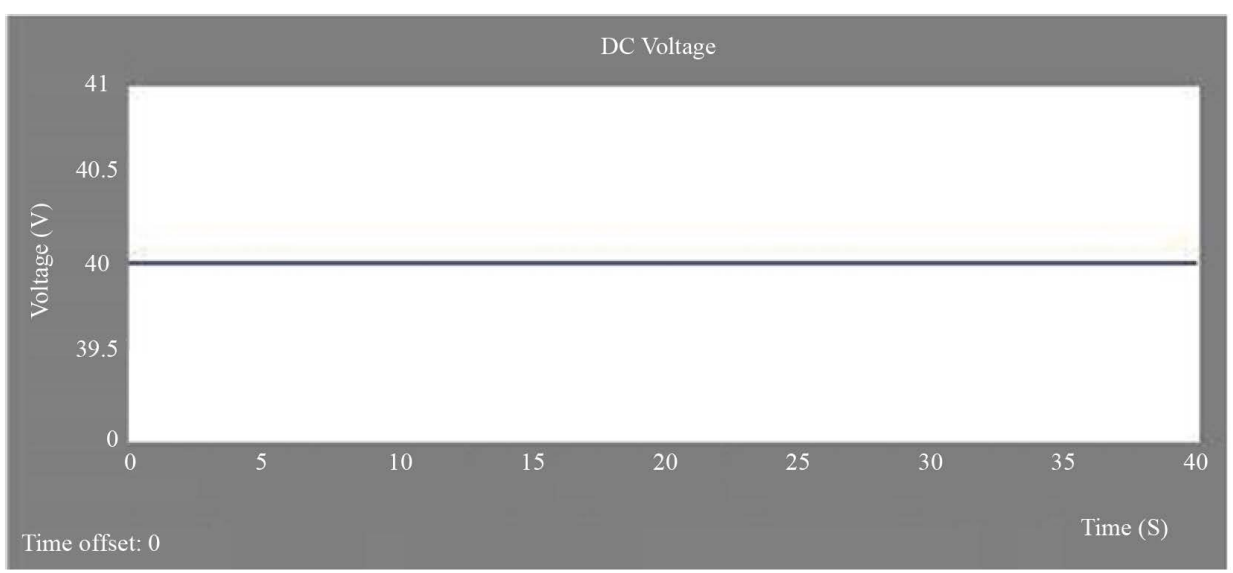

Figure 8. DC voltage waveform of four-switch three phase inverter. 
verter the input voltage is fed better one is obtained. Each phase can varied at the input voltage of $40 \mathrm{~V}$ which is shown in the Figure 9. It is carried out by voltage and time period the output of Phase A, B, C are structured by using Simulink model.

The main propose of this research is to concentrate on speed and backemf compared to conventional as in [13] [14]. To determine the speed all other parameters values are taken in to important consideration DC voltage of pure after from voltage regulation is inverted and is fed to Brushless motor three phase whose current are sensed by rotor position sensor whose phase currents are shown in Figure 10 and the speed of the motor is excellent enough achieved of $800 \mathrm{rpm}$ with less number of switching losses compared to six-switch inverter, which is shown in Figure 11.

In Figure 12, it is speed of $1450 \mathrm{rpm}$ is measured using tachometer compared to the Six switches our proposed work achieves less speed is achieved with low loss.

The trapezoidal Back Emf generated using four-switch inverter are shown in Figure 13 which is high enough generated by the controller to drive motor.

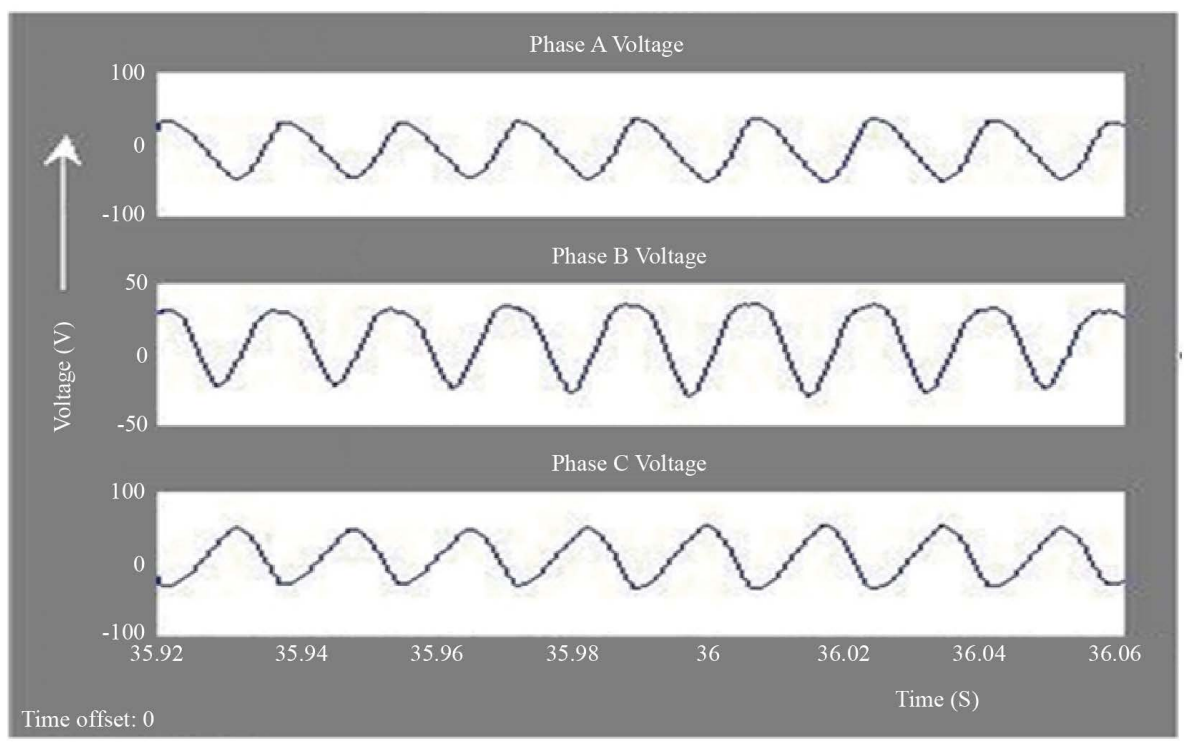

Figure 9. Phase voltage waveforms of four-switch three phase inverter.

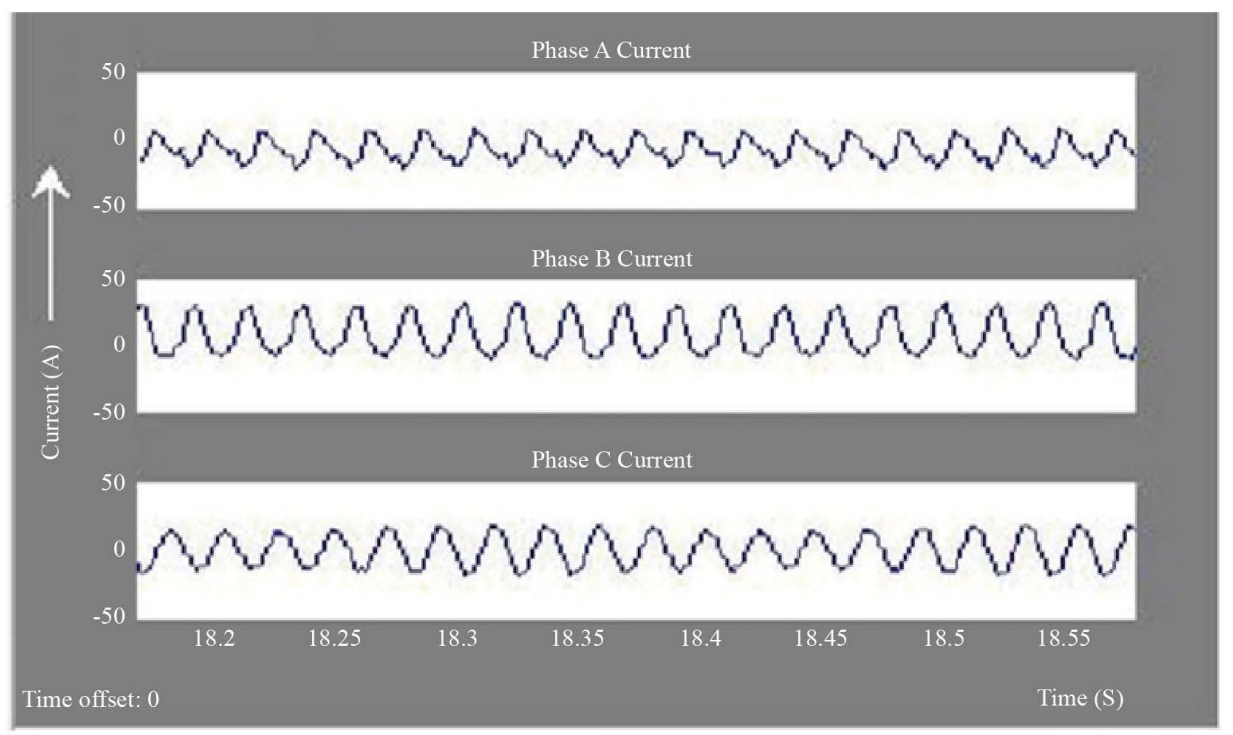

Figure 10. Phase current of the Sensorless four switch three phase inverter Brushless DC motor. 


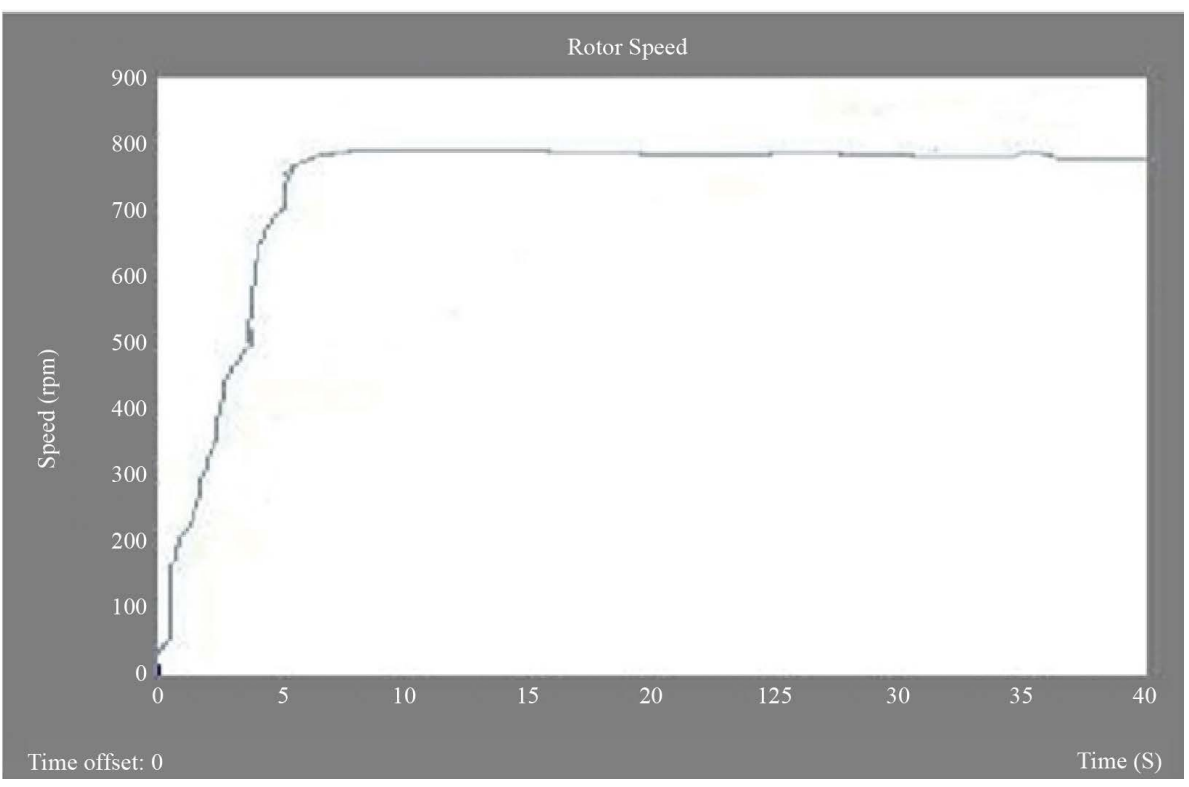

Figure 11. Speed of the Sensorless four-switch three phase inverter Brushless DC motor.
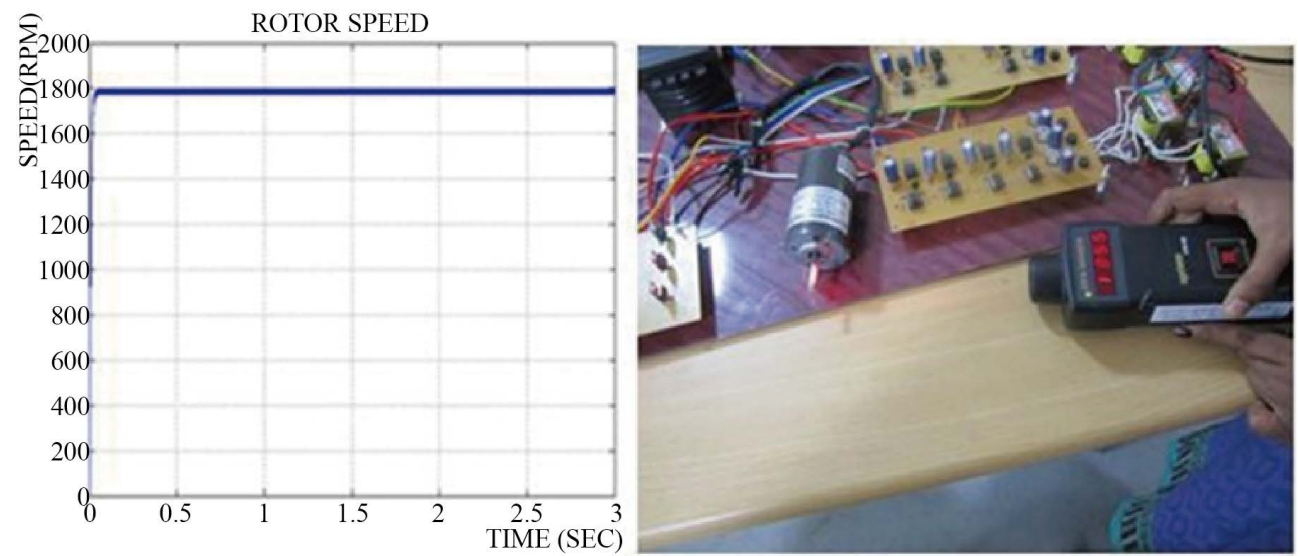

Figure 12. Speed response and phase current of the sensorless six-switch three phase inverter brushless DC motor.

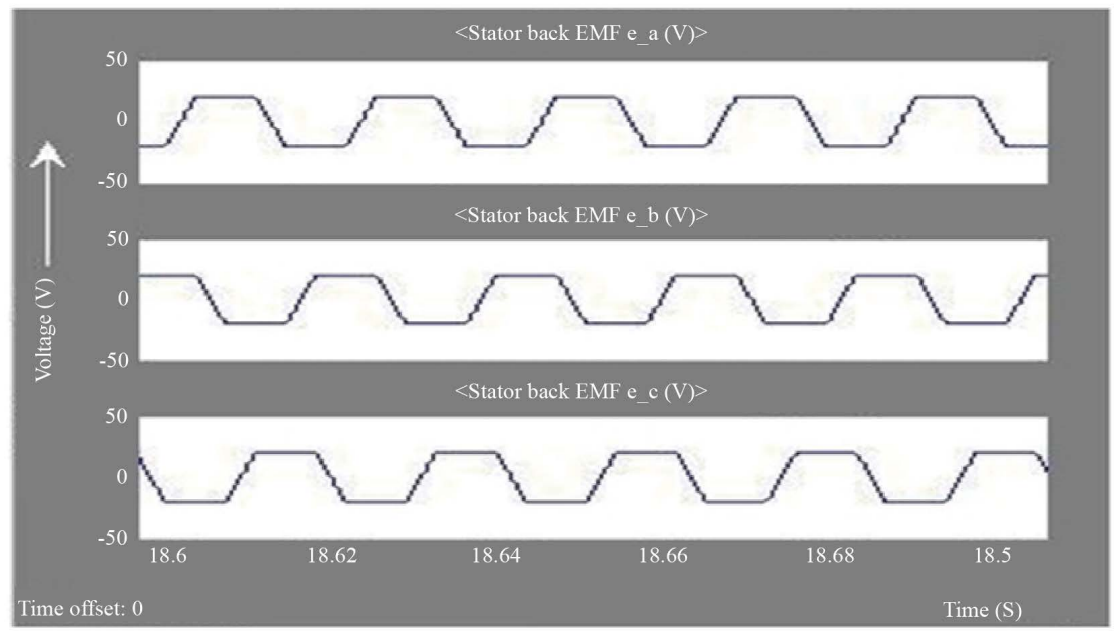

Figure 13. Back EMF of FSTPI brushless DC motor. 


\section{Conclusion}

In this research, we significantly use sensorless control so for angle position hall sensing fully avoided. Brushless DC drives which is preferable for compact, low maintenance and high reliability system in order to reduce the mechanical strength so it proposed and convenient simulation results are carried out. The simulation of the brushless DC motor is done using the software MATLAB/SIMULINK whose back EMF, phase voltage phase current, rotor speed waveform are analyzed and incorporated the speed of rotor is $800 \mathrm{rpm}$ are analysed. In this proposed converter used less number of insulated bipolar switches which evaluate the conventional converter. In this research, the back electromotive force compensating and direct current controlling for brushless DC motor drives analyzed and switch leg failure are avoided. In this scheme, the pulse width modulation is applied to high side switches of the converter. This pulse width modulation scheme can eradicate the offset voltage in the back electromotive force signal caused by the voltage drop of the insulated bipolar insulator and also increase system efficiency by reducing the conduction loss is achieved. This proposed converter used sensorless control operation. There are no hall sensors, therefore, the system becomes robust, optimized design of the brushless DC motor achieves higher efficiency and better speed, current is formulated.

\section{References}

[1] Bolfazl, H.N. (2008) A Novel Position Sensorless Control of a Four-Switch, Brushless DC Motor Drive without Phase Shifter. IEEE Transactions on Power Electronics, 23, 3079-3087. http://dx.doi.org/10.1109/TPEL.2008.2002084

[2] Young-Kuk, L., Tae-Hyung, K. and Ehsani, M. (2003) On the Feasibility of Four-Switch Three-Phase Brushless DC Motor Drives for Low Cost Commercial Applications: Topology and Control. IEEE Transactions on Power Electronics, 18, 164-172. http://dx.doi.org/10.1109/TPEL.2002.807125

[3] Lin, C.-K., Yu, J.-T., Fu, L.-C. and Liu, T.-H. (2012) A Sensorless Position Control for Four-Switch Three-Phase Inverter-Fed Interior Permanent Magnet Synchronous Motor Drive Systems. Proceeding of the IEEE/ASME International Conference on Advanced Intelligent Mechatronics (AIM), 1036-1041.

[4] Adauria, Y., Patel, A.N., Patel, V. and Patel, J. (2012) Simulation and Analysis of Three Phase Voltage Source Inverter Using Four Semiconductor Switches. Proceeding of the Engineering Nirma University International Conference on Engineering (NUiCONE), Ahmedabad, 1-14.

[5] An, Q.T., Sun, L., Zhao, K. and Jahns, T.M. (2010) Scalar PWM Algorithms for Four-Switch Three-Phase Inverters. Electronics Letters, 46, 900-902.

[6] Eltrao de Rossiter Correa, M., Jacobina, C.B., Cabral da Silva, E.R. and Lima, A.M.N. (2006) A General PWM Strategy for Four-Switch Three-Phase Inverters. IEEE Transactions on Power Electronics, 21, 1618-1627. http://dx.doi.org/10.1109/TPEL.2006.882964

[7] Xia, H.L., Li, Z.Q. and Shi, T.N. (2009) A Control Strategy for Four-Switch Three-Phase Brushless DC Motor Using Single Current Sensor. IEEE Transactions on Power Electronics, 56, 2058-2066.

[8] Lin, H.-T., Hung, C.-W. and Liu, C.-W. (2008) Position Sensor Less Control for Four-Switch Three-Phase Brushless DC Motor Drives. IEEE Transactions on Power Electronics, 23, 438-444. http://dx.doi.org/10.1109/TPEL.2007.911782

[9] Damodharan, P. and Vasudevan, K. (2010) Sensor Less Brushless DC Motor Drive Based on the Zero-Crossing Detection of Back Electromotive Force (EMF) from the Line Voltage Difference. IEEE Transactions on Energy Conversion, 25, 661-668. http://dx.doi.org/10.1109/TEC.2010.2041781

[10] Jung, D.-H. and Ha, I.-J. (2000) Low-Cost Sensor Less Control of Brushless DC Motors Using a Frequency-Independent Phase Shifter. IEEE Transactions on Power Electronics, 15, 748-752.

[11] El Badsi, B., Bouzidi, B. and Masmoudi, A. (2013) DTC Scheme for a Four-Switch Inverter-Fed Induction Motor Emulating the Six-Switch Inverter Operation. IEEE Transactions on Power Electronics, 28, 3528-3538. http://dx.doi.org/10.1109/TPEL.2012.2225449

[12] Geethu, J. and Radhakrishnan, K. (2013) Simulation of Four Switch Brushless DC Motor Drive. International Journal of Latest Trends in Engineering and Technology, 2, 100-106.

[13] Rajasekaran, P. and Vanchinathan, K. (2013) Improved Performance of Four Switch Three Phase Brushless DC Motor Using Speed-Current Control Algorithm. International Journal of Computer Applications, 68.

[14] Hoseinpour, A. (2010) Three Phase Active Filter with Four Switching Inverter and Variable Index Modulation. Proceeding of the 1st Power Quality Conference (PQC), Tehran, 1-7. 